\title{
Atividades de Proferição e Avaliação do Discurso (PAD) como instrumento de formação de professores
}

\author{
Production and evaluation of discourse as \\ a tool for teacher education
}

Márcia Sipavicius Seide*

Resumo: Neste artigo, será descrita e analisada a aplicação de uma atividade chamada Proferição e Avaliação do Discurso (PAD) desenvolvida num curso de Licenciatura de Letras. Essa atividade foi elaborada com o intuito de evidenciar a importância de o professor dominar gêneros retóricos orais com os quais possa persuadir e convencer seus alunos. Sua criação foi motivada pela percepção de que, independente da matéria que lecione, os bons professores realizam determinados gestos didáticos (DOLZ, et al., 2008): ao começarem a aula, eles chamam atenção dos educandos, motivando-os a colaborarem nas tarefas propostas e mantendo o interesse e a prontidão dos alunos ao longo da aula. Além disso, é mantida uma relação de confiança entre ambos e o domínio da disciplina e do tempo permite ao professor alcançar seus objetivos e finalizar a aula de modo satisfatório.

Palavras-chave: Retórica. Discurso. Gestos didáticos. Formação de professores.

Abstract: This paper analyzes the application of an activity called "Production and Evaluation of Discourse" (in Portuguese PAD) in an Undergraduate Language Course. This activity was designed to demonstrate the importance of teachers being able to produce speech in order to persuade and convince pupils. The activity was created based on the fact that despite the subject matter taught good teachers produce certain instructional gestures (DOLZ et al., 2008) when they start a class and when they call students' attention in order to motivate them to engage in the tasks proposed and maintain a high level of interest and readiness throughout the class. Moreover, a relationship of trust between teachers and students is kept, and the control of discipline and time allows the teacher to reach his or her goals and to finish the lesson in a satisfactory way.

Keywords: Rhetoric; Speech; Instructional Gestures; Teacher Education.

\section{Introdução}

Até 2004, o Colegiado de Letras da Unioeste, campus de Marechal Cândido Rondon, PR, oferecia curso de Licenciatura em Letras com habilitação

* Doutora em Letras, área de concentração em Filologia e Língua Portuguesa, USP. Docente do Mestrado em Letras da Universidade Estadual do Oeste do Paraná e do Curso de Graduação ofertado no campus de Marechal Cândido Rondon, PR. E-mail: marciaseda4@hotmail.com. 
única em Língua Portuguesa e Literatura Brasileira. Em 2005, extinguiu-se o curso com habilitação única e foi criado o curso com habilitação dupla: em Língua Portuguesa e Literatura mais uma língua estrangeira (alemão, espanhol ou inglês). Uma das mudanças ocorridas na grade foi a inclusão de uma disciplina chamada Retórica. Atualmente, uma nova grade está sendo implantada, implicando a exclusão dessa disciplina para dar lugar a disciplinas mais voltadas à descrição linguística, à gramática e aos estudos sintáticos. A experiência de se trabalhar com Retórica num curso de formação de professores de línguas, durante um período de seis anos, resultou na criação de uma ferramenta didática. Motivou este artigo a necessidade de registro, descrição e análise dessa ferramenta, que merece ser divulgada tanto pelos êxitos alcançados, quanto por ser ela aplicável a outras disciplinas de graduação que almejem contribuir para a formação de professores.

Nos Estados Unidos, a revitalização dos estudos retóricos durante as décadas de 60 e 70 do século passado motivou sua didatização e a Retórica foi usada para se ensinar estratégias persuasivas. Este movimento de aproximação ao mundo clássico com propósitos pedagógicos resultou na Nova Retórica baseada, principalmente, nos estudos de Toulmin (1958) e Perelman e Olbrechts-Tyteca (1996). Sob este prisma, a análise e a produção discursiva - tanto na fala, quanto na escrita - são entendidas em função do propósito e do contexto da argumentação. A preocupação da Nova Retórica com o contexto e o propósito da argumentação colocou em primeiro plano a situação social da qual emerge o discurso, evidenciando que o texto oral ou escrito que o constitui não se resume ao nível textual, como se fosse um mero artefato linguístico:

[...] conforme defende Toulmin, o que é avaliado como razoável ou convincente num contexto histórico, disciplinar e/ou social pode não ser em outro e, de acordo com Perelmam e Tyteca, o orador escolhe determinadas estratégias argumentativas em função de o que sabe ou imagina saber a respeito da audiência por ele pretendida (CARVALHO, 2005, p.131).

Nesse contexto, a colocação dos estudos retóricos como conteúdo programático de uma disciplina de Licenciatura em Letras pode ser entendida como decorrente dos desdobramentos resultantes da Nova Retórica. Outros fatores que influenciaram esta decisão estão relacionados à releitura que a Análise do Discurso fez de alguns conceitos retóricos e à relativa convergência entre os estudos sobre o gênero de inspiração bakhtiniana e os conceitos 
retóricos decorrentes da importância dada ao ouvinte para a conceituação e tipificação dos gêneros.

Desde o primeiro ano em que a disciplina foi ofertada, foi necessário relacionar os estudos retóricos à formação de professores de modo a justificar seu estudo aos graduandos, fazendo-os ver a importância da Retórica na profissão por eles pretendida. Por meio de reflexões e comentários feitos a partir das lembranças que os alunos têm de seus melhores professores, os alunos são levados a perceber que há algumas características em comum nos professores considerados excelentes. Ao começarem a aula, eles chamam a atenção dos alunos motivando-os a colaborarem nas tarefas propostas e percebe-se o interesse e a prontidão dos alunos ao longo da mesma. Além disso, é mantida uma relação de confiança entre ambos, e o domínio da disciplina e do tempo permite ao professor alcançar os objetivos propostos e finalizar seu trabalho docente de modo satisfatório.

As falas desses professores podem ser analisadas enquanto tipos de enunciado. Há enunciados para iniciar a aula, chamando a atenção do aluno; enunciados de motivação ao aluno; enunciados de chamada de atenção; e enunciados éthicos cujo propósito é construir o ethos do professor estabelecendo uma relação de confiança: a fides retórica. Estes tipos de enunciados foram classificados como gêneros retóricos orais. Com o intuito de evidenciar a importância de o professor dominá-los para assim poder conseguir persuadir e convencer os educandos, foi elaborada uma atividade de Prática de Ensino como Componente Curricular (APCC), chamada Proferição e Avaliação do Discurso $(\mathrm{PAD})$ que almeja atingir seus objetivos de modo prático, empírico e reflexivo.

Conforme se esclarece no Projeto Político-Pedagógico do curso:

[...] as atividades práticas, entendidas a partir da noção de prática como componente curricular, de acordo com o que prevê o parecer 28/2001, do Conselho Nacional de Educação, são desenvolvidas ao longo dos quatros anos do curso e estão vinculadas às disciplinas [...] como objetivo básico e norteador, as atividades práticas devem auxiliar na formação do acadêmico [...], elas objetivam, inclusive, a proposição de atividades que contribuam para reflexões e discussões em torno do ensino de língua materna e de língua estrangeira, atendendo ao exposto nas Diretrizes Curriculares para os Cursos de Letras (PROJETO POLÍTICO PEDAGÓGICO, 2004, s/p) 
Cumpre lembrar que o parecer 28/2001 do CNE está relacionado a mudanças na concepção dos cursos de licenciatura, os quais eram estruturados num esquema "três por um" (no qual as disciplinas voltadas à prática eram concentradas nos últimos anos do curso) que foi abolido a favor de outra concepção para a licenciatura. No modelo atual, as atividades voltadas à formação do educador têm início desde o primeiro ano da graduação mediante atividades de Prática como Componente Curricular, as quais devem totalizar, ao final da licenciatura, no mínimo, 400 horas, exigência que desafiou todos os professores do Colegiado de Letras a repensarem suas disciplinas e a refletirem sobre a contribuição de cada uma para a formação do educador.

\section{Descrição da atividade de Proferição e Avaliação do Discurso (PAD)}

Ao longo dos anos, a PAD passou por algumas modificações. Será apresentada, a seguir, a última versão dessa atividade, que vem sendo aplicada tal qual está descrita neste ano letivo (2010). A sala é dividida em oito grupos de até cinco componentes. A cada grupo é designado um gênero oral (discurso ou miniaula) e um assunto (mais ou menos polêmico para os discursos e um tópico visto em sala para as miniaulas). Explicita-se, então, o que se entende por cada tipo de apresentação. O discurso tem por objetivo conseguir a adesão dos espíritos, isto é, fazer com que a audiência compartilhe um ponto de vista sobre determinado assunto. Nesse tipo de apresentação, o orador monopoliza o turno. Na miniaula, determinado tópico deve ser ensinado de modo que os alunos aprendam e gostem da matéria, podendo haver alternância de turno: aluno-professor; professor-aluno.

Antes da apresentação oral, com quinze dias de antecedência, o grupo deve apresentar um trabalho escrito no qual deve constar a planificação da apresentação. Para o discurso, devem estar explicitados: o assunto, o objetivo, a escolha justificada das estratégias discursivas e dos materiais a serem utilizados, e uma descrição de como a apresentação começará, desenvolverse-á e terminará, acompanhada de explicações sobre quais são as expectativas do grupo. Ao final, devem constar as referências bibliográficas consultadas. Para a miniaula, é preciso entregar um plano de aula detalhado com as partes relativas a conteúdo, objetivos, procedimentos metodológicos, anexos (material utilizados, atividades e gabarito) e referências. Uma semana antes 
da apresentação, o trabalho escrito é devolvido ao grupo com comentários e sugestões. Explica-se que esta atividade é importante para garantir que a apresentação seja feita da melhor forma possível.

Após a apresentação, cuja duração pode variar de trinta a cinquenta minutos, há a fase de auto e de heteroavaliação. Nesta etapa, cada grupo deve responder a um questionário avaliativo: há um para o grupo que se apresentou e outro para os que assistiram.

Após quinze ou vinte minutos de troca de ideias sobre a apresentação e apontamentos preparatórios para a fala de avaliação, cada grupo expressa a avaliação feita, começando por aquele que se apresentou e terminando pela fala do docente que sintetiza os resultados, complementa as avaliações, faz reflexões e apresenta conclusões.

A partir das reações observadas pelo próprio orador e pelos demais componentes do grupo, grupo que fez a apresentação precisa perceber os pontos fortes e os pontos fracos da apresentação; avaliar em que medida a apresentação atingiu ou não os objetivos propostos e ser capaz de fazer uma autocrítica construtiva que inclua sugestões sobre o que pode ser feito futuramente em outras apresentações. Quanto aos demais grupos, se espera que consigam justificar as avaliações feitas apontando os fatores que levaram a ou impediram a adesão dos espíritos de modo honesto, sincero e respeitoso. Ao final, cabe ao docente avaliar as avaliações, sintetizar resultados e dar diretrizes para os próximos eventos de APCC (costuma haver, ao todo, oito apresentações ao longo da segunda metade do curso de 68 horas). Esta última parte é extremamente importante, já que é responsabilidade do professor fazer, da experiência, uma situação de ensino reflexiva e progressiva que consiga ir da prática à teoria e da teoria à prática.

Ao prepararem-se para a PAD de modo cuidadoso e pensando nas características da audiência, eles começam a perceber a necessidade de o professor preparar suas aulas em função dos alunos e não, necessariamente, daquilo que seria mais cômodo ao professor. Enfatizando-se a importância de se chamar a atenção da plateia e manter seu interesse, começa-se a pensar na questão importantíssima da motivação dos alunos durante as aulas.

Apresentar a autoavaliação e passar pela experiência de compará-la com as avaliações feitas pela audiência e pelo docente desenvolve a autocrítica, para o que se requer, além da capacidade de observação e interpretação 
de sinais, humildade e honestidade. Neste ponto, o desempenho dos alunos varia consideravelmente. A maioria dos alunos passa a perceber e a admitir as falhas cometidas; alguns são críticos demais, não percebendo os pontos fortes da própria apresentação e uma pequena minoria não se mostra capaz de autocrítica.

A prática de avaliar o trabalho do colega e depois ouvir a avaliação da avaliação feita pelo docente funciona como uma espécie de ensaio para tarefas inerentes ao fazer docente: avaliar as produções docentes e comunicá-las de modo proveitoso. Nos últimos eventos de PAD, foi possível perceber que os participantes passaram a apresentar maior senso crítico, mais habilidade avaliativa e uma preocupação maior por comunicar a avaliação feita de modo construtivo.

Para se der uma ideia de como os alunos avaliam a PAD, foi solicitado, no mês de maio de 2010, que duas alunas, escolhidas ao acaso, enviassem, por e-mail, um relato sobre a PAD realizada durante o segundo semestre de 2009. Se bem apenas dois relatos não sejam suficientes para que tenha uma avaliação da atividade do ponto de vista discente, eles podem fornecer alguns indícios dos aspectos que os alunos consideram mais importantes.

Uma das alunas, ao final de seu relato, qualifica a PAD como "uma atividade que não foi esquecida". Ao longo de sua narrativa ela explica o porquê:

[...] a atividade proposta [...] foi de grande espanto para toda a turma. Isto por que, quando o valor da atividade está relacionada a sua exposição oral, a grande maioria sentiu uma espécie de "incapacidade" de falar em público.O trabalho além de inovador, sobressaiu-se pelos muitos aspectos positivos que acarretou.O primeiro deles foi enfrentar o medo de falar em público. [...] Embora o grupo pudesse escolher quem seria o orador, houve alunos que compreenderam isto como um desafio, no qual mostraram, baseando-se nos pressupostos da retórica trabalhados em sala, sua capacidade para persuadir o público de seu ponto de vista. Em segundo lugar, elencaria o fato de este público ter participação concreta na avaliação dos trabalhos. Todos tiveram a oportunidade de colocar algumas ressalvas, apontar aspectos positivos ou negativos, bem como justificá-los. (ALUNA 01, maio de 2010)

Percebe-se, pelo relato dessa aluna, que vencer o desafio de falar em público e ter oportunidade de avaliar e ser avaliado foram os aspectos mais 
importantes da PAD. O segundo relato também aponta a dinâmica avaliativa como um ponto forte da atividade:

Eu considero muito importantes atividades realizadas em grupos, que possibilitem a interação entre os acadêmicos e o professor. Além disso, a questão de se obter um feedback após uma atividade realizada é sempre um momento especial de aprender algo ou de rever alguma informação que não ficou esclarecida ou que pode ter sido mal interpretada. Assim, avalio como positiva a iniciativa da realização dos seminários, ainda mais em uma disciplina como a Retórica, a qual trabalha justamente com a arte de persuadir [...]. Esta foi uma oportunidade excelente de autoavaliação, de avaliação grupal e, ainda, com o parecer do professor, então, uma avaliação global efetivamente, algo que raramente acontece e que deveria ser mais utilizado em sala de aula, a fim de promover a reflexão e a interação entre os acadêmicos e o professor (ALUNA 02, maio de 2010).

Descrevendo mais detalhadamente o comportamento de todos perante a avaliação, ela afirma:

O que mais chamou minha atenção foi que, após a realização de cada apresentação, os colegas dos demais grupos se reuniam e discutiam prováveis acertos e erros e, posteriormente, falavam ao grupo de forma aberta para toda a classe.

Naturalmente, nem sempre é fácil escutar críticas, mas neste caso, considero as críticas feitas construtivas, uma vez que todos os grupos fizeram colocações bem pertinentes e centradas, sem agressões pessoais, mas centrando-se no assunto em questão e na postura retórica de cada apresentador (ALUNA 02, maio de 2010).

Outro aspecto por ela apontado foi a eficácia da atividade do ponto de vista da aprendizagem dos conhecimentos específicos da disciplina: "Por fim, neste tipo de atividade evidencia-se também a apreensão dos conhecimentos relacionados à matéria que são colocados em prática tanto na hora da apresentação quanto no momento da avaliação, o que acredito ser também muito interessante" (ALUNA 02, maio de 2010). 


\section{A atividade de Proferição e Avaliação do Discurso e a Sequência Didática}

A PAD foi desenvolvida, aplicada e aperfeiçoada tendo-se por base os postulados retóricos. Contudo, o confronto desta prática com as propostas de aplicação ao ensino de línguas dos princípios do Sociointeracionismo discursivo (ISD), via construção de instrumentos de trabalhos pautados na Sequência Didática (SD), evidenciou muitos pontos em comum. Dada esta convergência, a PAD pôde ser analisada com base nas propostas da Equipe de Didática de Línguas da Universidade de Genebra.

Conforme explica Nascimento (2009b, p. 09), os módulos iniciais de uma SD estão organizados em três etapas: apresentação da situação, produção inicial e reconhecimento do gênero. Na primeira, apresenta-se aos alunos um problema a ser resolvido. Espera-se que cada um construa uma representação da situação de comunicação e da atividade de linguagem a ser executada. $\mathrm{O}$ propósito dessa etapa é expor o aluno a uma situação sócio-interativa que requeira a utilização de um gênero de texto de modo a motivá-lo a apropriar-se desse gênero.

Comparando-se a $\mathrm{PAD}$ à primeira etapa de uma $\mathrm{SD}$, percebe-se que, em ambos os casos, os alunos se defrontam com uma situação-problema que é preciso resolver. O aluno, futuro educador, se dá conta da necessidade de desenvolver determinadas habilidades discursivas e cognitivas, como saber motivar os alunos, saber avaliar suas reações, e, pela autocrítica, conseguir entender causas possíveis para as reações percebidas nos alunos. Dada essa situação, a proferição e avaliação do discurso surgem como uma ferramenta mediante a qual essas habilidades podem ser desenvolvidas.

Enquanto na SD há uma produção inicial individual que é avaliada mediante a aplicação de uma grade de avaliação diagnóstica, na PAD, a produção inicial é feita pelo primeiro grupo que se apresenta. Ao invés de todos os parâmetros estarem previamente determinados, há a construção coletiva e gradual de critérios a partir de alguns princípios retóricos. Antes das apresentações, são explicitados os seguintes princípios: a) as partes do discurso (invenção, elocução, disposição e ação) são criadas em função do ouvinte; b) deve haver preocupação tanto com o convencimento (logos) quanto com a persuasão (pathos); c) o orador precisa mostrar-se digno de confiança (fides); d) a apresentação oral deve apresentar as características do gênero oral pretendido; e) a apresentação oral precisa conseguir a adesão dos espíritos. 
A etapa posterior à de produção inicial é a de reconhecimento do gênero. Nessa fase da SD, os alunos são expostos a textos pertencentes ao gênero que se quer ensinar. Mediante observação e reflexão, os alunos fazem constatações que remetem às características do gênero e apontam para as suas exigências/coerções, as quais devem ser levadas em conta quando se pretende produzir um exemplar do gênero. $\mathrm{O}$ registro dessas constatações forma uma lista de constatação.

$\mathrm{Na}$ PAD, a exposição ao gênero ocorre toda vez que os discentes assistem às apresentações e o reconhecimento de suas características constitutivas se dá de modo gradual através da dinâmica de construção de critérios avaliadores da $\mathrm{PAD}$, a qual se assemelha à lista de constatação. Após cada grupo expor oralmente sua avaliação, o docente sintetiza as falas e faz comentários sobre as estratégias que deram bom resultado e aquelas cujo uso dificultou ou impediu a adesão dos espíritos. Estas falas finais concluem as reflexões feitas ao longo das atividades de Avaliação do Discurso Proferido.

São comentários que funcionam como as constatações. Uma vez que há um acordo sobre as exigências retóricas feitas, os próximos eventos de PAD devem adequar-se a elas. Um ponto sobre o qual sempre há acordo diz respeito à leitura durante as apresentações: após as primeiras apresentações, todos concordam que se deve evitá-la e, se isto não for possível, deve-ser entremeá-la de falas espontâneas. Trata-se de uma constatação que remete a uma característica importante de muitos gêneros textuais orais, com inclusão do Seminário Escolar, cujos princípios foram descrito por Gonçalves (2009).

As próximas etapas da SD são a das oficinas e a de produção final (NASCIMENTO, 2009b, p.70-71). Nas oficinas, trabalha-se com o resultado da avaliação diagnóstica: são atividades que visam fazer com que os alunos tenham os pré-requisitos necessários à produção de um texto do gênero textual escolhido. Na última etapa, todos os conhecimentos adquiridos devem culminar na produção textual final.

$\mathrm{Na} \mathrm{PAD}$, o papel das oficinas é cumprido pela experiência de proferir e avaliar discursos, repetidas vezes, e pelos eventos sucessivos e graduais da avaliação docente sobre a avaliação dos alunos. A produção final, em vez de ser uma segunda produção levada a cabo individualmente, equivale à melhor apresentação que a turma conseguiu produzir. É necessário enfatizar que a melhor produção é fruto de um trabalho coletivo, à medida que é alcançada mediante o reconhecimento coletivo das exigências retóricas da audiência particular para a qual as apresentações são feitas. 
A comparação da PAD com a SD evidencia também a existência de algumas diferenças em certos aspectos do processo avaliativo e no sistema de produção inicial e final. Não obstante essas diferenças, um e outro têm por base os mesmos princípios norteadores que aconselham que o processo de aprendizagem seja pautado por um momento inicial de produção textual, seguido de uma fase de exposição a exemplares do gênero, momentos de observação e reflexão sobre o que foi observado e um momento posterior de volta à produção textual. Conclui-se, então, que ambos os instrumentos são comparáveis entre si e estão regidos pelos mesmos princípios.

A utilização dos instrumentais fornecidos pelo Sociointeracionismo Discursivo para a análise da PAD esclarece por que os resultados alcançados têm sido promissores: o aluno é colocado perante situações sócio-interativas de uso dos gêneros e há reflexão sobre os efeitos alcançados pelas escolhas que resultaram na produção textual.

Também decorrente do viés sociointeracionista discursivo, é a noção de gestos didáticos, cuja análise em enquadres interativos possibilita um melhor entendimento daquilo que motivou a elaboração da PAD: a análise das falas dos professores considerados excelentes.

\section{Gêneros retóricos orais, gestos didáticos e enquadres}

Independente da matéria que lecione, os professores, ao utilizarem-se destes gêneros retóricos orais, realizam gestos didáticos (DOLZ, et al, 2008, apud NASCIMENTO, 2009a, p. 55) pelos quais o gênero do discurso e o gênero de atividade constituem-se mutuamente. Assim, entende-se que o objetivo principal da PAD é oportunizar aos graduandos a utilização e avaliação desses gestos levando em consideração que:

[...] para estudarmos o dizer na esfera da atividade escolar, o ponto de partida passa a ser o vínculo entre a utilização da linguagem e a atividade humana, o que conduz o enfoque aos modos de fazer e tipos de dizer no interior da atividade onde os enunciados emergem, se estabilizam, se adaptam e se transformam (NASCIMENTO, 2009a, p. 54).

Buscando investigar quais e como são os gestos didáticos que acompanham a aplicação da SD, Nascimento filmou e analisou uma aula dada por uma 
professora para o atual quinto ano do ensino fundamental. A professora estava fazendo um curso de formação continuada nos quais aprendeu como utilizar esta ferramenta didática em suas aulas. Em outro momento, a filmagem foi mostrada à professora que pôde prestar esclarecimentos sobre seus propósitos e intenções em cada gesto e fazer uma análise de seu fazer docente. Os gestos didáticos selecionados foram analisados levando-se em consideração a aula filmada, os procedimentos metodológicos propostos na SD e a autoanálise da professora. Deste modo, conforme a etapa focalizada pela professora, os enunciados selecionados foram analisados tendo-se de atribuir-lhe um enquadre.

$\mathrm{O}$ enquadre indica o sentido implícito da mensagem emitida ou recebida: da primeira perspectiva, mostra "como sinalizamos o que dizemos ou fazemos"; da segunda, indica "como interpretamos o que é dito ou feito". A introdução e a manutenção dos enquadres organizadores do discurso, por parte dos participantes de encontros face a face, são decorrentes das respostas dadas aos questionamentos sobre onde a interação está situada e sobre o que está acontecendo no momento e no lugar em que ela ocorre. (GOLFFMAN, 1989, p. 70, apud SEIDE, 2007). Um exemplo clássico é o do "macaco que precisa saber se uma mordida de outro macaco dever ser entendida dentro do enquadre de brincadeira ou do enquadre de luta. As pessoas constantemente se deparam com esta mesma tarefa interpretativa". (TANNEN; WALLAT, 1998, p. 123, apud SEIDE, 2007). Dado enunciado: é uma piada, é um insulto, ou ambos? Muitas brigas começam a partir deste último enquadramento.

Os primeiros enunciados receberam o enquadre 1: "Que gênero é esse?". Nesta parte da aula, a interação com os alunos objetivava motivá-los a refletirem sobre o gênero a que pertencia o texto que estavam lendo, um poema de João Cabral de Melo Neto. O enquadre 2, "A emergência de um problema metalingüístico", foi formado pelas interações que objetivavam a solução, por parte dos alunos, de uma dificuldade de compreensão do poema. No enquadre 3, "Argumentando sob um ponto de vista", a professora incitou os alunos a interpretarem o poema mediante hipóteses e questionamentos entre os educandos, mediante um "agir discursivo que leva ao encorajamento da tomada de posição, da justificativa do argumento e da contra-argumentação". (NASCIMENTO, 2009a, p.81). Os enunciados finais formaram o enquadre 4: "Chegando à solução do problema". Nesse momento, a professora retoma o que os alunos disseram e chega a uma conclusão sobre a interpretação do poema. O enunciado final deste enquadre foi analisado como um "relato de síntese integradora final". 
Chama a atenção o comportamento dos alunos em todos os enunciados selecionados. Há participação e colaboração de todos. Eles seguem as instruções dadas e parecem motivados na execução das tarefas solicitadas. Conseguir que os alunos comportem-se desta forma é uma conquista, é fruto de gestos didáticos anteriores pelos quais se consegue a adesão dos educandos. Os gêneros retóricos orais, objeto de ensino da PAD, fazem parte destes gestos didáticos que funcionam como pré-requisitos do trabalho docente.

Usando a noção de enquadre, pode-se propor uma categorização desses gestos: enquadre de chamada inicial de atenção; enquadre de colocação dos alunos em prontidão (isto é numa posição de poder e querer aprender o conteúdo a ser trabalho); enquadre disciplinar (advertências e outras providências para se manter a disciplina); enquadre motivacional; e, também, um enquadre mais amplo que abarca os demais: o de construção e manutenção da autoridade do professor.

\section{Considerações Finais}

O objetivo deste artigo foi o de apresentar uma ferramenta didática utilizada na disciplina de Retórica. Na introdução, contextualizou-se a criação da disciplina e o surgimento das Atividades Práticas com o Componente Curricular (APCC) nos cursos de Licenciatura, atividades das quais a ferramenta didática faz parte. Feita esta contextualização inicial, descreveu-se a Atividade de Proferição e Avaliação do Discurso (PAD).

Em seguida, ela foi comparada ao instrumento de Sequência Didática (SD) construído a partir das propostas do Sociointeracionismo Discursivo (ISD). Por fim, as falas tipificadas dos professores considerados excelentes, ponto de partida para a elaboração da PAD, foram analisadas enquanto gestos didáticos cujos enunciados foram categorizados em enquadres, sob inspiração das pesquisas de Nascimento (2009) a respeito do agir docente. As convergências encontradas levantaram a hipótese de haver uma fundamentação teórica também convergente.

Fazer uma descrição justificada da PAD provocou um distanciamento entre o sujeito-agente da atividade e seu produto, fazendo com que a PAD se constituísse num objeto de estudo. A avaliação e a análise feitas evidenciaram os pressupostos teóricos subjacentes, os quais, de outro modo, não teriam sidos trazidos à tona. 
Assim, pode-se concluir pela importância da contribuição do ISD não só para um melhor entendimento da $\mathrm{PAD}$, mas também, e talvez principalmente, para minha formação docente, uma vez que sua utilização motivou esta escritura reflexiva sobre as experiências realizadas.

Posso afirmar, então, que houve um retorno reflexivo sobre minhas próprias práticas. Na primeira seção do texto, houve uma teorização inicial de fundamentação para a prática; na segunda, a descrição desta prática, e, nas seguintes, a análise da prática de que resultou uma volta reflexiva em direção à teoria. Um retorno à prática, é o próximo passo a ser dado.

Nesse sentido, convém fazer algumas considerações sobre os desafios propostos por Dolz (2009) para a formação docente nos cursos de graduação. Um deles é o de garantir estes movimentos reflexivos teoria-prática e práticateoria. Tendo em vista esta experiência de análise de meu fazer docente, percebo que os desafios do ensino são essencialmente os mesmos independentemente do nível em que o professor lecione. São desafios que o professor universitário deve colocar-se a si mesmo para, então, poder desafiar seus alunos. Finalizo com as palavras de Dolz sobre esse desafio que:

[...] consiste en la puesta en práctica de la enseñanza, experimentando los principales gestos profesionales del profesor de lenguas. Se trata de pensar las modalidades de acompañamiento del profesor debutante por el formador y de asegurar un retorno reflexivo sobre las propias prácticas. Formar a partir del ejercicio de la actividad profesional, pero tratando de analizar las prácticas, con una vuelta reflexiva, por tanto, hacia la teoria. (DOLZ, 2009, p. 3) ${ }^{1}$.

\section{Referências}

BRASIL. Ministério da Educação. Conselho Nacional de Educação. Parecer CNE/CP No. 28/2001-MEC. Disponível em: http://portal.mec.gov.br/cne/arquivos/pdf/028.pdf. Acesso em: 10 maio 2010.

CARVALHO, Gisele de. Gênero como ação social em Miller e Bazerman: o conceito, uma sugestão metodológica e um exemplo de aplicação. In: MEURER, J. L. et al., (Orgs.). Gêneros: teorias, métodos, debates. São Paulo: Parábola Editorial, 2005.

\footnotetext{
${ }^{1}$ Consiste em pôr o ensino em prática, experimentando os principais gestos profissionais do professor de línguas. Trata-se das modalidades de acompanhamento do professor debutante pelo formador e de garantir que haja um retorno reflexivo sobre as próprias práticas. Formar a partir do exercício da atividade profissional, mas procurando analisar as práticas, com uma volta reflexiva, portanto, à teoria.
} 
DOLZ, Joaquim. Los cinco grandes retos de la formación del profesorado de lenguas. In: SIGET, SIMPÓSIO INTERNACIONAL DE ESTUDOS DE GÊNEROS TEXTUAIS, 5. Universidade de Caxias do Sul, Caxias do Sul, RS. 11 a 14 de agosto de 2009. Anais... [CD-ROM].

DOLZ, J.; GAGNON, R.; TOULOU, S. Production écrite et difficultés d'aprendissage. Université de Genève. Faculté de Psychologie et des Sciences de L'Éducation. 2008.

GOFFMAN, Erving. Footing. In: RIBEIRO, Branca Telles; GARCÉZ, Pedro M. (Orgs.). Sociolinguística interacional: antropologia e sociologia em análise do discurso. Porto Alegre: Age, 1998, p. 70-97. [Texto original publicado em Semiótica, vol.25, p. 1-29, 1979].

GONÇALVES, Adair. O gênero "seminário" como objeto de ensino-aprendizagem: modelo didático. In: SIGET, SIMPÓSIO INTERNACIONAL DE ESTUDOS DE GÊNEROS TEXTUAIS, 5. Universidade de Caxias do Sul, Caxias do Sul, RS. 11 a 14 de agosto de 2009. Anais... [CD-ROM].

PROJETO Político Pedagógico, Curso Letras - port/alemão/esp./inglês. Unioeste, Campus de Marechal Cândido Rondon, PR, 2004.

NASCIMENTO, Elvira Lopes. Gênero da atividade, gêneros textuais: repensando a interação em sala de aula. In: Gêneros textuais: da didática das línguas aos objetos de ensino. São Carlos, SP: Editora Claraluz, 2009a, p. 51-90.

Mediações formativas e apropriação de gêneros textuais. In: SIGET, SIMPÓSIO INTERNACIONAL DE ESTUDOS DE GÊNEROS TEXTUAIS, 5. Universidade de Caxias do Sul, Caxias do Sul, RS. 11 a 14 de agosto de 2009. Anais... [CD-ROM].

PERELMAN, Chaïm; TYTECA-OLBRECHTS, Lucie. Tratado da argumentação: a nova retórica. São Paulo: Martins Fontes, 1996.

SEIDE, Márcia Sipavicius. A interação entrevistador-informante numa comunidade de pescadores de Guaíra, PR. Línguas \& Letras. Cascavel, PR: Edunioeste, v. 8, n. 14, $1^{\text {º }}$. Sem. 2007, p. 147-161.

- Gênero e ensino no curso de licenciatura em letras: usando a retórica para formar professores. In: CIELLI (Colóquio Internacional de Estudos Linguísticos e Literários). Universidade Estadual de Maringá, 09 a 10 de junho de 2010. Comunicação Oral.

TANNEN, Deborah; WALLAT, Cynthia. Enquadres interativos e esquemas de conhecimento em interação: Exemplos de um exame consulta médica. In: RIBEIRO, Branca Telles; GARCÉZ, Pedro M. (Orgs.). Sociolinguística Interacional: antropologia, linguística e sociologia em análise do discurso. Porto Alegre: Age: 1998, p. 120-141. Social Psychology Quarterly, n. 50, v. 2, 1987, p. 205-216.

TOULMIN, Stephen. The uses of argument. Cambridge, UK: Cambridge University Press, 1958.

Recebido para publicação em 8 nov. 2010.

Aceito para publicação em 20 mar. 2011. 